\title{
Homology Modelling and in-silico analysis of 39bp Insertion-Deletion in Sahiwal Cattle SERPINA14 gene: The first report
}

\author{
P.B. Nandhini ${ }^{1}$, D. Ravikumar ${ }^{1}$, Oshin Togla ${ }^{1}$, M.R. Vineeth ${ }^{1}$, and ANUPAMA \\ MUKHERJEE ${ }^{1}$
}

${ }^{1}$ National Dairy Research Institute

April 28, 2020

\begin{abstract}
SERPINA14 proteins are progesterone induced and are secreted during pregnancy in large quantities by the endometrial epithelium. Serine proteinase inhibitor being represented only in a limited group of mammals has been associated with higher embryo survival rates, productive life, milk production and health traits and a minisatellite insertion has been reported in Bali cattle. The most variable exons ( 1 and 4 ) of SERPINA14 gene in Sahiwal cattle were sequenced to reveal the 39bp repeats in the coding region of the exon 4. In order to ascertain the changes in this gene that directly affects the protein structure, its structure was deduced using homology modelling with Bos taurus as reference, after imputing the missing coding sequence. The comparison of protein structure using SWISS-MODEL, I-TASSER and PHYRE2 showed that PHYRE2 predicted the best model for the proteinswith more than $90 \%$ of the residues lying in the most favoured regions in the Ramachandran plot.The impact of the indel with 5 repeats was assessed to be deleterious using PROVEANwith a score of -22.464 while indel with 4 repeats had a score of -10.676 against athreshold of -2.5 comparing with 130 sequences and 30 clusters. However, the association of the indel with reproduction data failed to reveal any significant effect which could be attributed to the data size. Phylogenetic study of the gene with its relatives showed that the sequence with 5 repeats was similar to Yak and Bison while the one with 4 repeats resembled all bovines alike.
\end{abstract}

\section{Hosted file}

Manuscript-Anupama.pdf available at https ://authorea.com/users/314797/articles/445211-homologymodelling-and-in-silico-analysis-of-39bp-insertion-deletion-in-sahiwal-cattle-serpina14-genethe-first-report 